\title{
Vitamin D Deficiency Among Afghan Adolescents in Kabul
}

\author{
Shabnam Azizi ${ }^{1}$ and Tariq Mahmud Tariq ${ }^{2}$ \\ Department of Clinical Laboratory $1 /$ Pathology ${ }^{2}$, French Medical Institute for Mothers and Children, Kabul, Afghanistan
}

\begin{abstract}
Objective: To determine vitamin D deficiency $(25-\mathrm{OH}-\mathrm{D}$ level $<20 \mathrm{ng} / \mathrm{ml}$ ) frequency among apparently healthy Afghan adolescents.

Study Design: Cross-sectional analytical study.

Place and Duration of Study: Pathology Department, French Medical Institute for Mothers and Children (FMIC) Kabul, from June to Sep 2016.

Methodology: Adolescents who reported for analysis of vitamin D level in their sera were included. Age, gender, duration of sun exposure, area of exposed skin, types of living and eating lifestyles were documented. Vitamin $D$ levels were measured by chemiluminescence method, using immunoassay autoanalysers. The participants were divided into five categories according to their serum vitamin D levels as sufficiency: $\geq 30-100 \mathrm{ng} / \mathrm{ml}$; insufficiency: $\geq 20-29 \mathrm{ng} / \mathrm{ml}$; deficiency: $<20 \mathrm{ng} / \mathrm{ml}$; severe deficiency: $<10 \mathrm{ng} / \mathrm{ml}$; and intoxication: $>150 \mathrm{ng} / \mathrm{ml}$. Participants who had vitamin $\mathrm{D}$ intoxication were excluded from the study.

Results: Out of 308 cases for final analysis, 202 (65.6\%) were females and 106 (34.4\%) were males. Of all, 238 (77.3\%) had a low level of vitamin D in their sera, whereas $70(22.7 \%)$ had vitamin D sufficiency. Among those having hypovitaminosis D, 107 (45\%) had severe deficiency, 81 (34\%) had deficiency and 50 (21\%) had vitamin D insufficiency. More pronounced lower levels were observed in females. Exposure to sun, use of a sun protector, vitamin D supplements, and vitamin D rich food intake, type of living, skin colour, and BMI of participants were seen as important factors linked to vitamin D levels.

Conclusion: Hypovitaminosis $D$ is prevailing among Afghan adolescents, more pronounced in girls. Wearing of traditional clothes, duration of sunlight, type of living and inadequate consumption of vitamin $D$ rich foods are significant determinants of hypovitaminosis D.
\end{abstract}

Key Words: Vitamin D, Prevalence, Deficiency, Associated factors, Afghan adolescents.

How to cite this article: Azizi S, Tariq TM. Vitamin D deficiency among Afghan adolescents in Kabul. J Coll Physicians Surg Pak 2019; 29(11):1072-7.

\section{INTRODUCTION}

The sunlight is by far the major source of vitamin $D(25-$ $\mathrm{OH}-\mathrm{D}$ ) in human body. It is synthesised on interaction of ultraviolet $B$ (UVB) rays of sun with 7-dehydrocholesterol present in the skin. It is also present naturally in some foods, but in small quantities. Furthermore, vitamin D supplements are available in medical stores. The important risk factors linked with vitamin D deficiency are little exposure to sun, atmospheric pollution, high rise buildings, skin pigmentation, indoor restriction during the day, and low physical activity. ${ }^{1-6}$ In nations like Afghanistan, social, ethnic and economic factors are considered to be the main barriers in obtaining sufficient quantity of this micronutrient from dietary sources. However, hypovitaminosis $D$ is now documented as a pandemic, both in developed as well as developing countries. Various studies have reported that vitamin D deficiency is prevalent among adolescents in the United

Correspondence to: Dr. Tariq Mahmud Tariq, 186-Eden

Avenue, Airport Road, Lahore, Pakistan

E-mail: tariq.fmic@yahoo.com

Received: March 08, 2019; Revised: July 25, 2019;

Accepted: July 25, 2019
States, where it is predominant during the winter and spring as compared to fall and summer. A study done on Turkish girls found that those wearing religious dress had vitamin D deficiency. ${ }^{7}$ Studies conducted in Iran estab-lished a high frequency of vitamin $D$ deficiency; the prevalence in Tehran healthy adolescents' girls was higher than boys. ${ }^{8,9}$ Studies conducted in different parts of Pakistan have also shown a high occurrence of hypovitaminosis D.10-12 In India, studies from many parts of the country have also reported a high prevalence of hypovitaminosis $D$ in their youths. ${ }^{13,14}$

Vitamin $D$ deficiency is fairly prevalent all over the globe. However, data about vitamin D status among Afghan adolescents is lacking due to scarcity of research on the subject.

Therefore, the objective of the present study was to determine the status of vitamin $D$ deficiency among apparently healthy adolescents reporting to a tertiary care facility in Kabul and to identify factors that represent forecasters for hypovitaminosis $D$ in the study population.

\section{METHODOLOGY}

It was a cross-sectional analytical study conducted at Pathology Department, French Medical Institute for 
Mothers and Children (FMIC) Kabul, from June to Sep 2016. Approval for the study was obtained by Ethical Committee of the Institute and Ministry of Public Health (MoPH), Afghanistan.

All adolescents (both boys and girls) between 10 and 18 years of age, who reported or were referred to Hospital Laboratory of French Medical Institute for Mothers and Children for determination of vitamin D (25-OH-D) level in their sera were included in the study. A total of 310 adolescents participated during study period. Two of the participants, who had vitamin $\mathrm{D}$ intoxication $(25-\mathrm{OH}-\mathrm{D}$ level of $>150 \mathrm{ng} / \mathrm{ml}$ ), were excluded from the study and; hence, 308 was the size of the sample for the final analysis. Individuals with celiac disease, Crohn's disease, cystic fibrosis, who had history of past surgery that removed or bypassed portions of the stomach or intestines, who had history of pituitary gland problem, asthma, kidney diseases and other chronic diseases and all those who were not willing to participate in the study, were excluded. To find the factors linked with vitamin $D$ deficiency, various clinical and demographic characteristics of adolescence, including age, gender, educational level, skin colour, body mass index (BMI), type of living, outdoor activity, sun exposure, type and usage of sun protectors, use of vitamin $D$ rich foods or supplements and surgical procedure were noted. Data was collected for participants from the day of appointment, including contact number, age, sex, and selfdeclared lifestyle. Participants were asked to complete questionnaires concerning their nutritional intake, physical activity during the the day, and assessment of suplement intake. Determination of 25-OH-D level was carried out by collecting $5 \mathrm{ml}$ of blood in SST (Serum Separator Tube) provided by BD Vacutainer $($ ) from each participant at the time of visit. The sample tube was centrifuged and serum 25-OH-D measurement was carried out by chemiluminescence immunoassay using ADVIA Centaur analyser supplied by Siemens. The participants were divided into five categories according to $25-\mathrm{OH}-\mathrm{D}$ levels in their sera: 1 ) Sufficiency: $\geq 30-100$ $\mathrm{ng} / \mathrm{ml}$; 2) Insufficiency: $\geq 20-29 \mathrm{ng} / \mathrm{ml}$; 3) Deficiency: $<20 \mathrm{ng} / \mathrm{ml}$; 4) Severe deficiency: <10 ng/ml; and 5) Intoxication: $>150 \mathrm{ng} / \mathrm{ml}$.

Descriptive and inferential statistics were used for data analysis. The analysis was done using Statistical Package for the Social Science (SPSS) version 21. Level of 25$\mathrm{OH}-\mathrm{D}$ was considered as variable and proportion was described. A p-value of $<0.05$ was considered as statistically significant. To determine the association of independent variables with $25-\mathrm{OH}-\mathrm{D}$ level, Chi-square test of independence was carried out.

\section{RESULTS}

The results of vitamin $D$ measurements revealed a mean value of $21.82 \mathrm{ng} / \mathrm{ml}$, with median value of $14.94 \mathrm{ng} / \mathrm{ml}$; maximum and minimum values being $115.28 \mathrm{ng} / \mathrm{ml}$ and
$4.20 \mathrm{ng} / \mathrm{ml}$, respectively. Of all, $238(77.3 \%)$ of adolescents had a low level of vitamin $D$ in their sera. A high number of $107(34.7 \%)$ participants had severe deficiency, $81(26.3 \%)$ had deficiency, $50(16.2 \%)$ had insufficiency, whereas only $70(22.7 \%)$ had sufficiency.

Table I shows the inferential statistics for the association between vitamin $\mathrm{D}$ status and clinical demographic variables of the study participants. Majority of those, i.e., $202(65.6 \%)$ were females and $106(34.4 \%)$ were males, with a female to male ratio of 1.9:1. The mean age of the sample was $14.39 \pm 2.82$ years with median age of 14 years. A large number of participants, i.e. 162 (52.6\%), were educated and had sufficient information about vitamin D. Many of the participants, i.e. $136(44.2 \%)$, had fair skin color and the rest categories of skin color were almost equally distributed among the remaining. Most of the study subjects, i.e. $195(63.3 \%)$, had normal body Mass Index (BMI), whereas $85(27.6 \%)$ were either overweight or obese and $28(9.1 \%)$ were found to be underweight. A majority of the participants, i.e. 198 (64.3\%), were living in yards while $110(35.7 \%)$ were living in apartments. A high proportion of adolescents, i.e. $234(76 \%)$, had outdoor activity (with the mean of 3.12 hours), while the remaining had no or less than measurable amount of outdoor activity. Exposure to sunlight was not observed in $118(38.3 \%)$ of the study subjects. Conversely, the rest $190(61.7 \%)$ had exposure to the sunlight. Among the participants who had sun exposure, only $54(17.5 \%)$ of them had sunlight exposure to the whole body and $136(44.2 \%)$ of them had exposure only to face and hands. The amount of sun exposure was measured as minute/day and 118 $(38.3 \%)$ had sun exposure of $<5$ minutes/day, which was considered as no sun exposure; whereas among participants who had sun exposure, $112(36.4 \%)$ had $>30$ minutes/day and the rest $78(25.3 \%)$ had $6-15$ minute/day. Half of the participants, i.e. 154 (50\%), were regular users of sun protectors and the rest $50 \%$ were not regular users of sun protectors. Out of those who were regular users of sun protectors, $70(22.7 \%)$ were using sunscreen, $48(15.6 \%)$ were wearing heavy clothes, and $36(11.7 \%)$ were using both. The intake of supplemental calcium with vitamin $D$ was seen only in $108(35.1 \%)$, while $200(64.9 \%)$ were not receiving any supplemental calcium+vitamin D. A high percentage of the participants, i.e. $217(70.5 \%)$, were identified as individuals who took regular milk intake. The frequency of the Omega-3 intake and history of surgical procedure were observed in a minority of the individuals, i.e. $19(6.2 \%)$ and $11(3.6 \%)$, respectively.

Table I also describes the association between independent variables and outcomes of vitamin $D$ status among Afghan adolescents. Significant associations were found with gender, exposure to sunlight, use of sun protector, heavy clothes, skin color, BMI, type of living, and diet. 
Table I: Inferential statistics for the association between vitamin D status and clinical demographic variables of adolescents visiting FMIC ( $\mathrm{n}=308$ ).

\begin{tabular}{|c|c|c|c|c|c|}
\hline \multirow[t]{2}{*}{ Characteristics } & \multicolumn{5}{|c|}{ Vitamin D level cut off } \\
\hline & $\begin{array}{l}\text { Sufficiency } \\
(\geq 30 \mathrm{ng} / \mathrm{ml} \text { ) }\end{array}$ & $\begin{array}{c}\text { Insufficiency } \\
(\geq 20-29 \mathrm{ng} / \mathrm{ml})\end{array}$ & $\begin{array}{c}\text { Deficiency } \\
(<20 \mathrm{ng} / \mathrm{ml})\end{array}$ & $\begin{array}{l}\text { Severe deficiency } \\
\quad(<10 \mathrm{ng} / \mathrm{ml})\end{array}$ & p-value \\
\hline \multicolumn{6}{|l|}{ Gender } \\
\hline Male $(n=106)$ & 32 & 20 & 42 & 12 & $<0.001$ \\
\hline Female $(n=202)$ & 38 & 30 & 39 & 95 & \\
\hline \multicolumn{6}{|l|}{ Age in year } \\
\hline Mean (SD) & $14.36(2.919)$ & $14.24(2.994)$ & $13.84(2.857)$ & $14.90(2.577)$ & 0.081 \\
\hline \multicolumn{6}{|l|}{ Education level } \\
\hline Yes (educated) & 42 & 18 & 42 & 60 & 0.055 \\
\hline No (uneducated) & 28 & 32 & 39 & 47 & \\
\hline \multicolumn{6}{|l|}{ Sun exposure } \\
\hline Yes & 50 & 34 & 42 & 64 & 0.044 \\
\hline No & 20 & 16 & 39 & 47 & \\
\hline \multicolumn{6}{|c|}{ Exposed area of the body to the sunlight } \\
\hline All the body & 24 & 4 & 14 & 12 & $<0.001$ \\
\hline Face and hand & 26 & 30 & 28 & 52 & \\
\hline No exposure & 20 & 16 & 39 & 43 & \\
\hline \multicolumn{6}{|l|}{ Amount of sun exposure } \\
\hline$>30$ minute/day & 38 & 12 & 18 & 38 & $<0.001$ \\
\hline 6-15 minute/day & 12 & 22 & 24 & 26 & \\
\hline$<5$ minute/day & 20 & 16 & 39 & 43 & \\
\hline \multicolumn{6}{|l|}{ Usage of sun protector } \\
\hline Yes & 18 & 28 & 39 & 69 & 0.003 \\
\hline No & 52 & 22 & 42 & 38 & \\
\hline \multicolumn{6}{|l|}{ Kind of sun protector } \\
\hline No sun protector & 52 & 22 & 42 & 38 & $<0.001$ \\
\hline Sun screen & 8 & 22 & 16 & 24 & \\
\hline Heavy clothes & 10 & 4 & 8 & 26 & \\
\hline Both & 0 & 2 & 15 & 19 & \\
\hline \multicolumn{6}{|l|}{ Skin colour } \\
\hline White & 18 & 6 & 2 & 20 & 0.004 \\
\hline Fair & 34 & 28 & 36 & 38 & \\
\hline Light brown & 8 & 10 & 23 & 25 & \\
\hline Dark brown / black & 10 & 6 & 20 & 24 & \\
\hline \multicolumn{6}{|c|}{ Calcium+vitamin D supplement intake } \\
\hline Yes & 44 & 22 & 26 & 16 & $<0.001$ \\
\hline No & 26 & 28 & 55 & 91 & \\
\hline \multicolumn{6}{|l|}{ Daily milk intake: } \\
\hline Yes & 60 & 30 & 65 & 62 & $<0.001$ \\
\hline No & 10 & 20 & 16 & 45 & \\
\hline \multicolumn{6}{|l|}{ Vit $D$ rich food intake } \\
\hline Yes & 66 & 36 & 59 & 57 & $<0.001$ \\
\hline No & 4 & 14 & 22 & 50 & \\
\hline \multicolumn{6}{|l|}{ Omega 3 intake } \\
\hline Yes & 8 & 0 & 2 & 9 & 0.024 \\
\hline No & 62 & 50 & 79 & 98 & \\
\hline \multicolumn{6}{|l|}{ Body Mass Index } \\
\hline Normal weight $(\geq 5-85 \%)$ & 70 & 31 & 36 & 59 & $<0.001$ \\
\hline Underweight $(<5 \%)$ & 0 & 0 & 12 & 16 & \\
\hline Overweight (>85-95\%) & 0 & 19 & 29 & 25 & \\
\hline Obese (>95\%) & 0 & 0 & 5 & 7 & \\
\hline Type of living & & & & & \\
\hline Yards & 52 & 40 & 49 & 57 & 0.002 \\
\hline Apartments & 18 & 10 & 32 & 50 & \\
\hline Surgical procedure & & & & & \\
\hline Yes & 0 & 0 & 4 & 7 & 0.054 \\
\hline No & 70 & 50 & 77 & 100 & \\
\hline Outdoor activity & & & & & \\
\hline Yes & 56 & 40 & 64 & 74 & 0.241 \\
\hline No & 14 & 10 & 17 & 33 & \\
\hline
\end{tabular}


There were no meaningful differences between age of the participants and serum vitamin $D$ levels $(p=0.081)$. There was also no statistical association between vitamin D status and education of the participants. Surgical procedure, too, was not found significant $(p=0.054)$. Likewise, there were no significant associations were found between the outdoor activities and serum $25-\mathrm{OH}-\mathrm{D}$ levels $(p=0.241)$.

\section{DISCUSSION}

Hypovitaminosis $D$ is now documented as a pandemic both in developed as well as developing countries. Sunlight is by far the main source of vitamin D. Very few foods naturally contain vitamin $D$, and foods that are fortified with vitamin $D$ are insufficient to meet the requirements of vitamin $D$. In a review done by International Osteoporosis Foundation (IOF), hypovitaminosis $\mathrm{D}(25-\mathrm{OH}-\mathrm{D}$ level $<30 \mathrm{ng} / \mathrm{ml})$ was prevalent in many regions of the world, whereas severe vitamin $D$ deficiency (25-OH-D level $<10 \mathrm{ng} / \mathrm{ml}$ ) was most common in South Asia and the Middle East. ${ }^{15} \mathrm{~A}$ study conducted in a high-risk population at a peak season for vitamin $D$ deficiency concluded that the population of children between 6 months to 5 years of age living in Kabul was at great risk of developing vitamin $D$ deficiency. ${ }^{16}$ To the best of our understanding, this is the first study to evaluate the status of vitamin $D$ in Afghan adolescents.

The findings of our study revealed that nearly threequarters of Afghan adolescents residing in Kabul province had varying degrees of hypovitaminosis $\mathrm{D}$. We found a significant association between gender and serum 25-OH-D concentration. Females were more predisposed to severe vitamin $\mathrm{D}$ deficiency than males. Similar findings were found in many studies conducted in neighbouring countries. ${ }^{7-9}$ The possible causes of severe vitamin $D$ deficiency among female adolescents might be due to decreased syntheses of vitamin $D$ in their skin as a result of reduced sun exposure, wearing religious clothes (which cover all the body), usage of sun screens and more time spent indoors. However, more studies are required to explain the possible causes of hypovitaminosis $\mathrm{D}$ among Afghan female adolescents.

The influence of sunlight on vitamin $D$ status in humans is well recognised and confirms the significance of sunlight exposure in the synthesis of vitamin D. Our study showed that sunlight exposure was one of the dominant factors of vitamin $D$ status in Afghan adolescents living in Kabul province. The duration of sunlight exposure and exposed skin area correlates with vitamin $\mathrm{D}$ levels. Such correlation has also been shown in many other studies. ${ }^{17-19}$

A darker skin requires more sun exposure than lighter skin to produce equal amount of vitamin. The avoidance of sun light due to anxiety of blackening of skin and covering of whole body conscientiously, especially in females when going outside, were the key factors. Male subjects also avoid sun exposure due to misconception regarding harmful effects of sunlight and unawareness regarding the source of Vitamin D. Consistent with the previous findings in the literature, the current study also suggests that usage of any kind of sun protector (sun screen, heavy clothes or both) is positively linked with mild to severe hypovitaminosis D. 20

Dietary intake was another contributing factor regarding high prevalence of vitamin $D$ deficiency, since most of these participants were consuming low amount of milk, and foods containing natural quantity of vitamin $D$. Factual assessment of vitamin $D$ intake was not possible due to ignorance about amount of diet intake by participants and unobtainability of food composition catalog for vitamin D used in Afghanistan. It has been suggested that Omega-3 intake is positively associated with vitamin $D$ status. ${ }^{21}$ This study also ratified the same. Although a large number of participants did not have information about Omega-3 and therefore, this variable was not focused. However, among the adolescents who used Omega-3, most of them did not have hypovitaminosis-D.

The use of supplements is mostly a health and lifestyle choice. Reduced intake of vitamin D supplements, especially in the context of Afghanistan, is possibly due to socio-economically disadvantaged population. In this study, a significant association was observed in supplement intake and vitamin D status. Among those who regularly had supplement intake, most of them had vitamin D sufficiency. However, among adolescents who did not take any supplement, a high percentage had severe vitamin $D$ deficiency. Thus our study reveals that supplementation of calcium and vitamin $D$ has an important role in culmination of vitamin $D$ deficiency.

The required dose of UVB is lower in individual with white skin, compared to those with dark skin. The possible cause of vitamin $\mathrm{D}$ deficiency among darker skin persons might be that larger amounts of melanin pigment interfere in the absorption of UVB in the skin. It has been studied that ultraviolet rays are reduced maximum by black fabric and minimum by white clothes. ${ }^{22}$ In this region, a noteworthy section of women wear dusky clothes customarily for veiling while outside. Our study is congruent with the literature that persons with darker skin colour have more marked vitamin $D$ deficiency than persons with lighter skin colour. 23

Serum 25-OH-D level is inversely linked with BMI. The explanation of this could be that the amount of vitamin D synthesised is diluted in the body of obese individuals than individuals with normal weight. Capacity of skin for production of vitamin $D$ is not affected by obesity but obesity might have effects on release of vitamin $D$ from the skin into the blood circulation. The findings of our study were consistent with previous studies. ${ }^{24}$ 
The physical activity decreases calcium excretion and increases absorption ability thus increasing serum calcium, which results in sparing serum vitamin D. 25 The current study findings, however, suggested no relationship between outdoor activities and serum vitamin D concentration. Likewise, our results showed that there is no meaningful difference between age of the participant and serum vitamin $D$ level. Surgical procedure was not found significant too. Furthermore, no statistical association between vitamin D status and education of the participant was found.

One limitation of the present study was that a single determination of serum 25-OH-D level was done, which might not accurately reflect vitamin $D$ status for the whole year; at least two samples should have been taken in different months of the year to determine seasonal variation. Other limitations were that parathyroid hormone (PTH) and bone turnover markers were not studied as indicators of vitamin $D$ status.

\section{CONCLUSION}

Hypovitaminosis D is present in Afghan adolescents residing in Kabul province, more marked in girls. Wearing of traditional clothes, duration of sunlight exposure, and inadequate intake of vitamin $D$ rich foods and supplements are significant determinants of vitamin $D$ status. Future studies are needed to find out the seasonal variation; and to provide a fuller picture of the burden of vitamin $D$ deficiency among population of all ages. Besides, behaviour recommendations to maximise skin production of vitamin $D$, public health efforts should be focussed to educate people on the use of vitamin $D$ adjuncts foods and supplements to improve vitamin D levels in Afghan population who are at risk of developing vitamin $\mathrm{D}$ deficiency.

\section{ETHICAL APPROVAL:}

Ethical approval was obtained from Ethical Review Committee (ERC) of French Medical Institute for Mothers and Children, Kabul, Afghanistan prior to initiation of the research work.

\section{PATIENTS' CONSENT:}

Informed consents were obtained from the study participants to publish their data.

\section{CONFLICT OF INTEREST:}

Authors declared no conflict of interest.

\section{AUTHORS' CONTRIBUTION:}

SA: Carried out the study, analysed the data, and aided in writing the manuscript.

TMT: Conceived the study, was supervisor of overall planning/direction and wrote the manuscript.

\section{REFERENCES}

1. Al-Daghri NM. Vitamin D in Saudi Arabia: Prevalence, distribution and disease associations. J Steroid Biochem Mol Biol 2018; 175:102-7.

2. Kapil U, Pandey RM, Goswami R, Sharma B, Sharma N, Ramakrishnan $L$, et al. Prevalence of vitamin $D$ deficiency and associated risk factors among children residing at high altitude in Shimla district, Himachal Pradesh, India. Indian J Endocrinol Metab 2017; 21:178-83.

3. Kaddam IM, Al-Shaikh AM, Abaalkhail BA, Asseri KS, Al-Saleh YM, Al-Qarni AA, et al. Prevalence of vitamin D deficiency and its associated factors in three regions of Saudi Arabia: A crosssectional study. Saudi Med J 2017; 3818753:381-90.

4. Vierucci F, Del Pistoia M, Fanos M, Gori M, Carlone G, Erba P, et al. Vitamin $D$ status and predictors of hypovitaminosis $D$ in Italian children and adolescents: a cross-sectional study. Eur $J$ Pediatr 2013; 172:1607-17.

5. González-Gross M, Valtueña J, Breidenassel C, Moreno LA, Ferrari $M$, Kersting $M$, et al. Vitamin $D$ status among adolescents in Europe: The healthy lifestyle in Europe by nutrition in adolescence study. Br J Nutr 2012; 107:755-64.

6. Kumar J, Muntner P, Kaskel FJ, Hailpern SM, Melamed ML. Prevalence and associations of 25-hydroxyvitamin D deficiency in US children: NHANES 2001-2004. Pediatrics 2009; 124: e362-e70.

7. Hatun S, Islam Ö, Cizmecioglu F, Kara B, Babaoglu K, Berk F, et al. Subclinical vitamin $D$ deficiency is increased in adolescent girls who wear concealing clothing. J Nutr 2005; 135:218-22.

8. Tabrizi R, Moosazadeh M, Akbari M, Dabbaghmanesh $\mathrm{MH}$, Mohamadkhani M, Asemi Z, et al. High prevalence of vitamin D deficiency among Iranian population: A systematic review and meta-analysis. Iran J Med Sci 2018; 43:125-139.

9. Rabbani A, Alavian SM, Motlagh ME, Ashtiani MT, Ardalan G, Salavati $A$, et al. Vitamin $D$ Insufficiency among children and adolescents living in Tehran, Iran. $J$ Trop Pediatr 2009; 55: 189-91.

10. Mahmood K, Akhtar ST, Talib A, Haider I. Vitamin-D status in a population of healthy adults in Pakistan. Pak J Med Sci 2009; 25:545-50.

11. Khan AH, Jabbar A, Baig P. Vitamin D deficiency osteomalacia: the continuing challenge. J Coll Physicians Surg Pak 2008; 18: 664-6.

12. Iqbal $R$, Khan A. Possible causes of vitamin D deficiency (VDD) in population residing in Pakistan. J Pak Med Assoc 2010; 60: 1-2.

13. Soliman A, Sanctis V, Elalaily R, Bedair S, Kassem I. Vitamin D deficiency in adolescents. Indian J Endocrinol Metab 2014: 18(Suppl 1):S9-S16.

14. Soliman A, Kalra S. Adaptation to vitamin D deficiency: Age specific clinical presentations. Indian J Endocrinol Metab 2013; 17:775-9.

15. Mithal A, Wahl DA, Bonjour JP, Burckhardt P, Dawson-Hughes B, Eisman JA, et al. IOF committee of scientific advisors (CSA) nutrition working group. Global vitamin D status and determinants of hypovitaminosis D. Osteoporosis Int 2009; 20: 1807-20. 
16. Manaseki-Holland S, Zulf MM, Bhutta Z, Qasem SM. Vitamin D status of socio-economically deprived children in Kabul, Afghanistan. Int J Vitam Nutr Res 2008; 78:16-20.

17. Eloi M, Horvath DV, Szejnfeld VL, Ortega JC, Rocha DA, Szejnfeld J, et al. Vitamin D deficiency and seasonal variation over the years in Sao Paulo, Brazil. Osteoporos Int 2016; 27:3449-56.

18. Buttriss JL. Vitamin D: Sunshine vs. diet vs. pills. Nutr Bull 2015; 40:279-85.

19. Nimitphong $\mathrm{H}$, Holick MF. Vitamin D status and sun exposure in Southeast Asia. Dermatoendocrinol 2013; 5:34-7.

20. Al-Mutairi N, Issa BI, Nair V. Photoprotection and vitamin D status: A study on awareness, knowledge and attitude towards sun protection in general population from Kuwait, and its relation with vitamin D levels. Indian J Dermatol Venereol Leprol 2012; 78:342-9.
21. Al-Shaer AH, Abu-Samak MS, Hasoun LZ, Mohammad BA, Basheti IA. Assessing the effect of omega-3 fatty acid combined with vitamin D3 versus vitamin D3 alone on estradiol levels: a randomized, placebo-controlled trial in females with vitamin D deficiency. Clin Pharmacol 2019; 11:25-37.

22. Salih FM. Effect of clothing varieties on solar photosynthesis of previtamin D3: an in-vitro study. Photodermatol Photoimmunol Photomed 2004; 20:53-8.

23. Libon F, Cavalier E, Nikkels AF. Skin color is relevant to vitamin D synthesis. Dermatology 2013; 227:250-4.

24. Rashid S, Khurshid R. Amir UF, Rashid SMQ, Hajra B, Ali MA. Association between decrease in serum vitamin $D$ level and increase in body mass index. Gomal J Med Sci 2017; 15:110-4.

25. Soam SS, Sing TO, Chatuvedi S, Sarkar G. A study on association of degree of physical exercise and plasma $25(\mathrm{OH})$ vitamin D levels. Indian J Med Biochem 2018: 22:90-93. 